\title{
How to Face Loss: A Case Study on the Self-evolution of Empty-nesters Whose Children Are Abroad
}

\author{
Wang Tangsheng ${ }^{1}$, Ding Yicheng ${ }^{2}$, Jiang Mingzhuang ${ }^{3}$, Tang Jianing ${ }^{4}$, \\ ${ }^{1}$ School of Marxism, Wuhan University of Technology, Wuhan, China \\ ${ }^{2}$ Shanghai Foreign Language School, Shanghai, China \\ ${ }^{3}$ School of Law, Humanities and Sociology, Wuhan University of Technology, Wuhan, China \\ ${ }^{4}$ School of Foreign Languages and Literature, Wuhan University, Wuhan, China
}

Email address:

tangjianing@whu.edu.cn (Tang Jianing)

${ }^{*}$ Corresponding author

\section{To cite this article:}

Wang Tangsheng, Ding Yicheng, Jiang Mingzhuang, Tang Jianing. How to Face Loss: A Case Study on the Self-evolution of Empty-nesters Whose Children Are Abroad. Humanities and Social Sciences. Vol. 9, No. 5, 2021, pp. 136-144. doi: 10.11648/j.hss.20210905.12

Received: August 5, 2021; Accepted: August 31, 2021; Published: September 7, 2021

\begin{abstract}
Many researches have been conducted on the elders to find out what they do after they are left in the nursing homes and without any relatives, but there has been little focus on the relationship between the researchers and the elder people. Under this circumstance, we are here to try to figure this out. This research conducted ethnographic methods to study the self-evolution of empty-nesters, by observing and interviewing an empty nester whose children are abroad 41 times for 43 months. The background is in a Wuhan nursing home, where most residents only can communicate to their fellow residents, the staff and the interviewers. The have little communication with their children and when they do it will be via phone. The results found that the presence of the children who is highly recognized in their career or in their personality and other things by the individual cases and the presence of the researcher talking and interviewing them reduced their sense of reality and increased the possibility of conflict with others around her. The study concluded that the loss of important social relations caused the loss of their self-value, and eventually led to emotional and cognitive impairment, continuous elderly observation was of great significance to both the researchers and the subjects.
\end{abstract}

Keywords: Loss, Self-evolution, Sense of Reality, Object

\section{Introduction}

What does human's inner world look like after the old age? With the arrival of aging society, the research of aging psychology becomes more important. According to the literature analysis, the main focus of the research on aging psychology in the Chinese literature is on the word known as "raising" of family pension, social pension, home pension, and pension mode, and the verb shows the relationship between the donor and the recipient. In terms of how to support the elderly, there may be many considerations related to living style, living arrangement, rural and urban pension relations, social support and intergenerational support, as well as subjective happiness and life satisfaction in different pension relationships [1].

In English literature (web of science), related topics to aging are more negative emotional words, aging is associated with various psychological diseases. Aging research is associated with child development, adolescents, adults, etc, as a reference to other groups rather than focus. The topics concerned with the elderly such as pension, hospice care, and burying the death are relatively weak [2].

Studies in English try to eliminate old age, take aging as a process and deny the existence of a stage of aging. Some researchers argued that if the label effect of aging, the disease and health problems are eliminated, the elderly can even do what they could 20 years ago [3]. Neugarten [4] also argued that aging is a life-span developmental process rather than some special stages or different groups, and she even thought that the concept of Gerontology should be ended. However, the elderly in the nursing home is not only in a continuous aging process, but also indeed a group of elderly people who 
have lost their ability to live independently. Entering the caring institutions is a stage for the elderly. It cannot be denied that the fourth age has some common psychological traits of the elderly.

At the age of losing their ability, the old people have no distinction between success and failure. They can only rely on the actions of the other actors [5]. According to our previous research, in China, the relationship between children and their parents may largely affect the extent of Alzheimer's disease, so the elderly interpersonal relationship (parent-child relationship, social attitude, hospice care, death education) may be the most important research theme of geriatric psychology in China.

In the English literature, researchers need to try to exclude the relationship between the investigator and the respondent, because the relationship affects the results, but in fieldwork, especially the elderly in China, the respondents' self representations change according to the closeness of relationship with the investigators, and what the say to acquaintances often include complain, pain, and sorrow, rather than being positive and optimistic as they represent to strangers. In all, in the context of global-localization (called glocalization), if the elderly psychological research in China continues to follow the mainstream aging psychological research paradigm of English literature, it will not be conducive to the combination with pension practice and the development of action research. Reflecting the research background of the relationship between the investigator and the respondent on a gradual basis, we will observe the elderly in a daily situation for a long time and across several scenes, then adopt Psycho-dynamic analysis to explain the contents of diverse expressions of the respondent.

\section{Research Methods and Objects}

\subsection{Research Method}

Using ethnography, this research conducts a long sustained, muti-surfaced observation. The methods of obtaining the data include natural behavior observation, participatory observation, informal interview, formal interview, third party observation, etc. The data content includes the economic status of the research objects, social support system, daily activities, physical health status, mental health status, interpersonal interaction status, etc.

\subsection{Study Subject}

Elderly people living in nursing homes for a long time, their children being abroad, and are willing to receive observation and interviews for a long time. The main case $M$ in this study lasted 3 years and 7 months (43 months) from the first meeting to the last interview, with recorded number of 41 observations or interviews, at average of once per month.

\subsection{Analysis Tools}

Using Nvivo as the qualitative material analysis tool, the interview text was encoded primary, spindle and core coded.

The relationship of observers and observed cases is analyzed using relevant concepts of object relation theory of Kelly-construct approaches, Constructive developmentalism, and Psychoanalysis.

\section{Results}

\subsection{Observation Process}

Table 1 is the observation process of case $\mathrm{M}$, including the number of observations, time, location, people involved, key points of conversation, interaction with others, and researcher evaluation of the development status of $M$ self-realistic function. Among them, the R1, R2.....R13 symbolize the observers involved in the study who visited the $M$ in turn, $M$ means the case, the $\mathrm{W}$ president, $\mathrm{H} 1$ boss, $\mathrm{H} 2$ represent other staff of the nursing homes, and Q, $\mathrm{H}$ and others are all elderly people living in the nursing homes.

Table 1. Observation process of case $M$.

\begin{tabular}{|c|c|c|c|c|}
\hline $\begin{array}{l}\text { Number of } \\
\text { times }\end{array}$ & Time & Location & People & Talking points \\
\hline 1 & $3 / 11 / 2016$ & $\begin{array}{l}\text { The first floor hall of } \\
\text { the nursing home }\end{array}$ & $\begin{array}{l}\text { Dean of } \mathrm{R} 1 \text {, } \\
\mathrm{M}, \mathrm{W}\end{array}$ & $\begin{array}{l}\text { The growth and future of the children. There is still a clear memory of their young ideals, } \\
\text { such as engineers, pilots, etc., only to add regret. }\end{array}$ \\
\hline 2 & $3 / 18 / 2016$ & $\begin{array}{l}\text { Activity room on the } \\
\text { third floor of the } \\
\text { nursing home }\end{array}$ & $\begin{array}{l}\text { All the old } \\
\text { people in } \mathrm{R} 1 \text {, } \\
\mathrm{M} \text {, }\end{array}$ & $\begin{array}{l}\text { Participating in the activities of the nursing home, } \mathrm{R} \text { as a representative of the observer } \\
\text { spoke, the old man basically did not hear or understand. M retold R's statement. }\end{array}$ \\
\hline 3 & $4 / 1 / 2016$ & $\begin{array}{l}\text { Activity room on the } \\
\text { first floor of the } \\
\text { nursing home }\end{array}$ & $\begin{array}{l}\text { M, television } \\
\text { watching old } \\
\text { man, card } \\
\text { playing old } \\
\text { man }\end{array}$ & $\begin{array}{l}\text { On the first floor watching the movies on the disc are W } 1 \text { mother-in-law, W } 2 \\
\text { mother-in-law, T mother-in-law and other people, L father watching with W } 2 \text { mother-in-law } \\
\text { while doing a certain explanation, M also stand aside to watch. W } 2 \text { mother-in-law played } \\
\text { cards with the other two mother-in-laws in the community, Y } 1 \text { mother-in-law, X } \\
\text { mother-in-law and others are playing mahjong, M and others watching aside. }\end{array}$ \\
\hline 4 & $4 / 18 / 2016$ & $\begin{array}{l}\text { Activity room on the } \\
\text { third floor of the } \\
\text { nursing home }\end{array}$ & $\mathrm{R} 1, \mathrm{Q}, \mathrm{M}, \mathrm{H}$ & $\begin{array}{l}\text { After taking a picture with } \mathrm{Q}, \mathrm{M} \text { said he was not willing to take a photo together because of } \\
\text { his sick and bad appearance. } \mathrm{H} \text { it is best to keep the person he met in his memory. There is } \\
\text { no need to take photos if you can remember. Let it go if you can't remember. }\end{array}$ \\
\hline 5 & $4 / 27 / 2016$ & $\begin{array}{l}\text { Individual rooms for } \\
\text { the elderly in the } \\
\text { nursing homes. }\end{array}$ & $\mathrm{R} 1, \mathrm{R} 2, \mathrm{H}, \mathrm{M}$ & $\begin{array}{l}\mathrm{R} 1 \text { introduced } \mathrm{R} 2 \text { to the site. H mother-in-law did her a favor and led her to her room, to the } \\
\text { roof, and to M for interviews. }\end{array}$ \\
\hline 12 & $1 / 7 / 2017$ & $\begin{array}{l}\text { Second floor access } \\
\text { to the nursing home }\end{array}$ & $\begin{array}{l}\mathrm{R} 1, \mathrm{M}, \mathrm{M} \text { 's } \\
\text { brother-in-law }\end{array}$ & $\begin{array}{l}\text { M's brother-in-law sends the money over and asks } \mathrm{M} \text { to sign it. It turned out that M took } \\
\text { money, he forgot, wronged her brother-in-law for hiding. }\end{array}$ \\
\hline
\end{tabular}




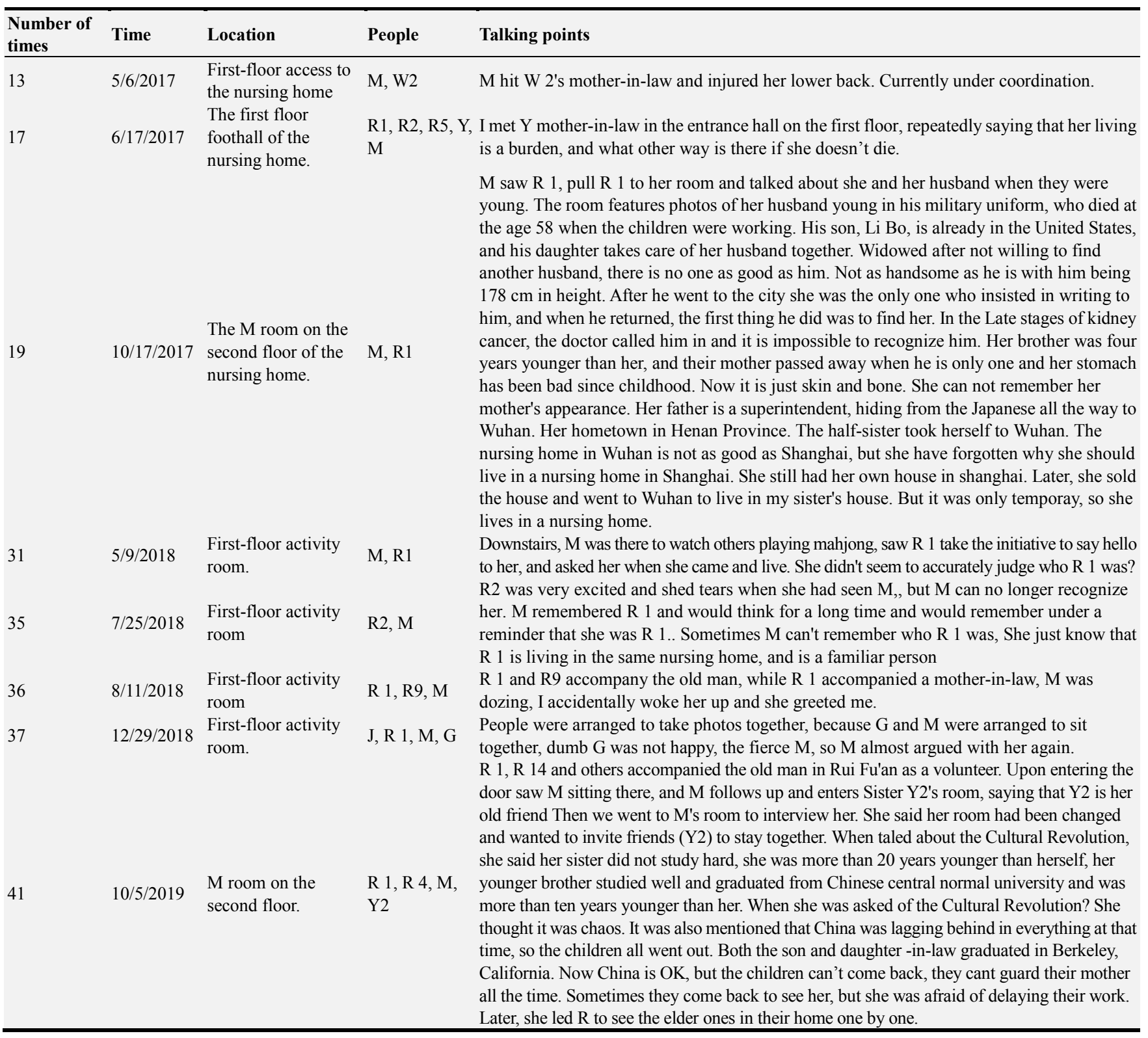

Table 1. Continue.

\begin{tabular}{|c|c|c|c|}
\hline $\begin{array}{l}\text { Number } \\
\text { of times }\end{array}$ & Time & Interaction with the actions of others & Self-evolution assessment \\
\hline 1 & $3 / 11 / 2016$ & $\begin{array}{l}\text { She first saw her when she was preparing for a haircut and } \mathrm{M} \text { had joking } \\
\text { and physical interaction with other old people }\end{array}$ & Memory basically stayed in forty years ago \\
\hline 2 & $3 / 18 / 2016$ & $\begin{array}{l}\text { M expresses that older people are not very impatient and do not recognize } \\
\text { her conductive role. }\end{array}$ & M's retelling concise and understandable. \\
\hline 3 & $4 / 1 / 2016$ & $\begin{array}{l}\text { Watch only, not participating. Others sat, and she stood. Seems intended to } \\
\text { keep the distance. }\end{array}$ & \\
\hline 4 & $4 / 18 / 2016$ & If you are going to leave a photograph, might as well leave the best one. & \\
\hline 5 & $4 / 27 / 2016$ & H's mother-in-law regarded $\mathrm{M}$ as a literate person. & \\
\hline 12 & $1 / 7 / 2017$ & $\begin{array}{l}\text { When the child comes back to visit her, she is emotional and prone to } \\
\text { conflict with other people. }\end{array}$ & $\begin{array}{l}\text { Has the wronging her brother-in-law had anything to do } \\
\text { with his children coming back? }\end{array}$ \\
\hline 13 & $5 / 6 / 2017$ & When the child comes back to visit her, she is emotional and prone to conflict & \\
\hline 17 & $6 / 17 / 2017$ & $\begin{array}{l}\text { R2 suggests giving them the video chat device, just as } \mathrm{M} \text { is passing through } \\
\text { and lets her down and get M's children's phone. R1 suggests that an } \\
\text { intervention therapy can be conducted. }\end{array}$ & $\begin{array}{l}\text { M's mother-in-law has revealed a lot of her emotional } \\
\text { language expressions, she has some regrets, said she } \\
\text { feels that she shouldn't speak about it. }\end{array}$ \\
\hline 19 & $10 / 17 / 2017$ & $\begin{array}{l}\text { She misses her children and wants to reunite with them for a while, but } \\
\text { know it can't happen. Every Monday, she calls, and is unwilling to answer } \\
\text { the videophone, if she answers she will cry, which destroys her calm mood. }\end{array}$ & $\begin{array}{l}\text { She cant remember lots of things and she can only mark } \\
\text { things on the calendar. She thinks that she can only stay in } \\
\text { America for a year or two and she can no longer return to } \\
\text { china, and she can only live for two or three years' time. }\end{array}$ \\
\hline
\end{tabular}




\begin{tabular}{|c|c|c|c|}
\hline $\begin{array}{l}\text { Number } \\
\text { of times }\end{array}$ & Time & Interaction with the actions of others & Self-evolution assessment \\
\hline 31 & $5 / 9 / 2018$ & M expects $\mathrm{R} 1$ to live in. & $\begin{array}{l}\text { May have seen R } 1 \text { insert photos into the door of the } \\
\text { atrium, and mistook a misunderstanding as the truth. }\end{array}$ \\
\hline 35 & $7 / 25 / 2018$ & Oblivion on emotionally dependent but unstable objects. & \\
\hline 36 & $8 / 11 / 2018$ & & $\begin{array}{l}\text { It was the first time she is discovered aking her nap } \\
\text { outside }\end{array}$ \\
\hline 37 & $12 / 29 / 2018$ & $\begin{array}{l}\text { G was young, and lived in a nursing home using labor to pay for his living } \\
\text { expenses, G was dumb and still despises } \mathrm{M} \text {, this can show what status } \mathrm{M} \\
\text { has in the nursing home. }\end{array}$ & \\
\hline 41 & $10 / 5 / 2019$ & $\begin{array}{l}\text { Before and after, Y2 expressed his despise towards M, but outwardly, } \\
\text { people are getting along with each other. }\end{array}$ & \\
\hline
\end{tabular}

From the observation record above, in the course of three and a half years, M's relationship with others goes through a process of difference, distance, conflict to apparent consistency and harmony, In the evolution of the self, $M$ has experienced many losses. Mainly it is the emotional instability caused by the loss of child companionship (object instability), Most of the strongest moments of M's conflict with those around them revolve around object instability. Whenever her son comes back to home to visit her, or when the young $\mathrm{R}$ comes over to have a long conversation, Her conflict with others around her will intensify, demonstrating serious cognitive impairment, including groundless suspicion of others, physical conflicts with others. In the following words, the researchers will present autobiographical charts of $M$ at the beginning of the interview and during intense conflict periods, thus finding the law of the self-evolution of $\mathrm{M}$ with interpersonal interaction and time.

\subsection{Word Analysis}

Three interviews with the initial observation (11 March 2016) and middle period (9 February 2018, 28 March 2018) are selected here. In the text tag, M means women, MZR is the full code of $\mathrm{M}$, and the final number string is the expression of Chinese habits.

The following are the background and content encoding presentation of the interview, respectively. R 1 first met $M$ when she was preparing for a haircut, and $M$ had jokes and physical interaction with other elderly people. She told R 1 about the growth of her children and their future, and still had clear memories of her young ideals, such as engineers, pilots, etc., only with regrets. The details are shown in Figure 1.

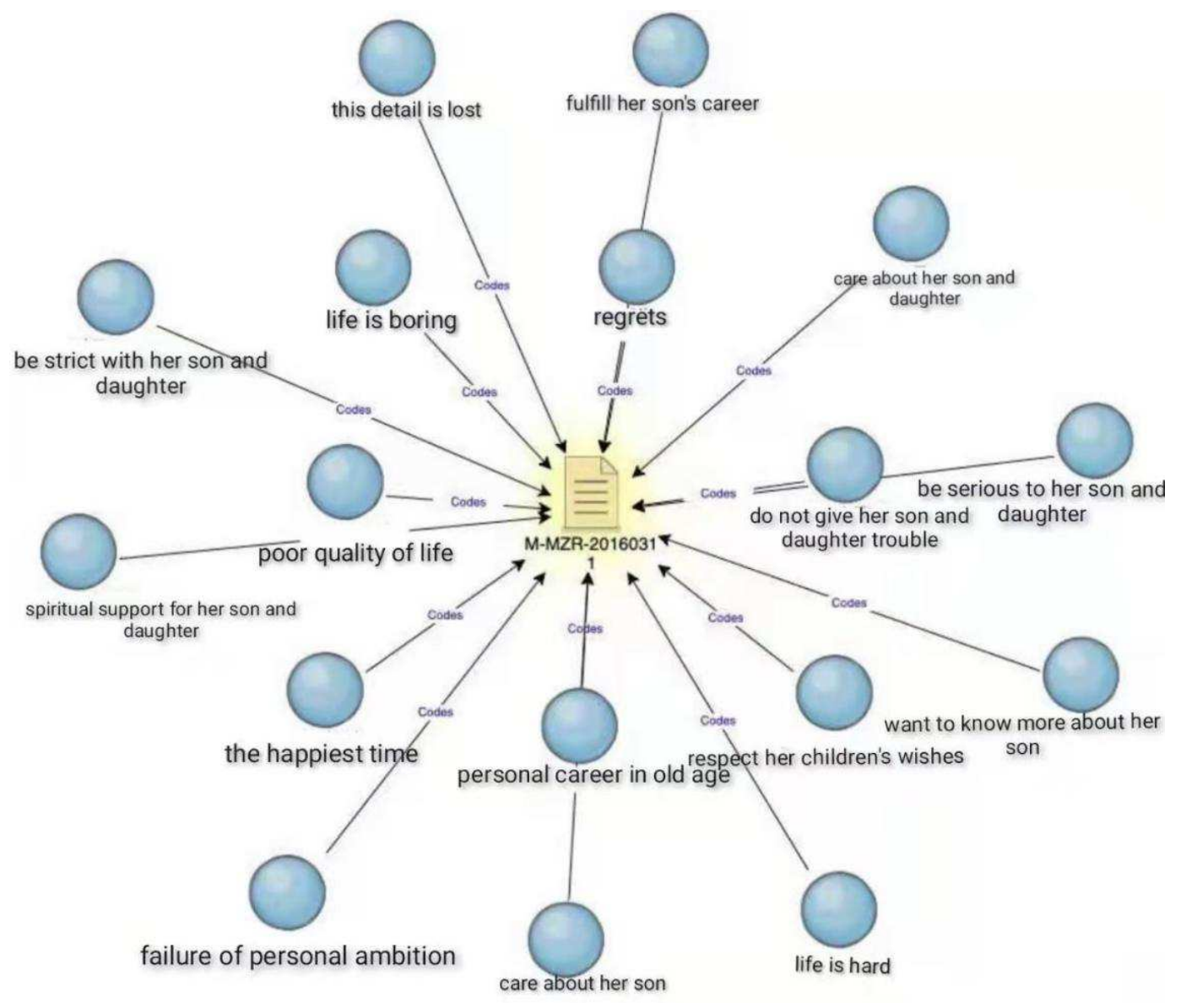

Figure 1. Key points of M self-narration during the initial interview. 
On the morning of February 9, 2018, R 1, R6, R7 et al. went to the nursing home to interview with $\mathrm{M}$. In the $\mathrm{M}$ room, she was lying in bed, we came to her room and she started making it, and wanted to find us a chair. The interview lasted about 100 minutes. M did not talk about the children this time, but the great three year famine. Talking about failing to realize her ambition to college and being Meculin because of family difficulties, about supporting younger brothers and sisters, about the despair and struggle of her husband's demobilization to rural Shanghai. Later, when she said that her son was admitted to Shanghai Jiao Tong University and went abroad, after graduation. she simplified a lot to his child's preparation for high school. Maybe he realized that R 1 had heard it many times, or that we basically did not respond. Later, she talked about her mother died when she was young and continuous escaping during the Japanese invasion, said that her husband died from cancer and took out her husband's photos and showed them to us. Knowing that the two high school students are ready to go abroad, she talked about the china's outflow talents and the wisdom of America attracting talented people, this can be regarded as thinking about the future of the nation! Finally, she expressed high expectations to R6 and R7. R 1 goes downstairs and sees W2, after greeting her, M kept trying to send the R $\mathrm{s}$ to the door. See Figure 2 for the main points of this interview.

At the training center of the nursing staff, the staff member $\mathrm{G}$ heard that we have talked with $\mathrm{M}$, and then said from her observation that $\mathrm{M}$ was very bad with dementia, often thinking that others took her things, and said that she gets along badly with others everywhere, and their children did not want to take her to the United States, which surprised us. G said that M says the same thing to everyone everyday, it was very annoying, like a performance.

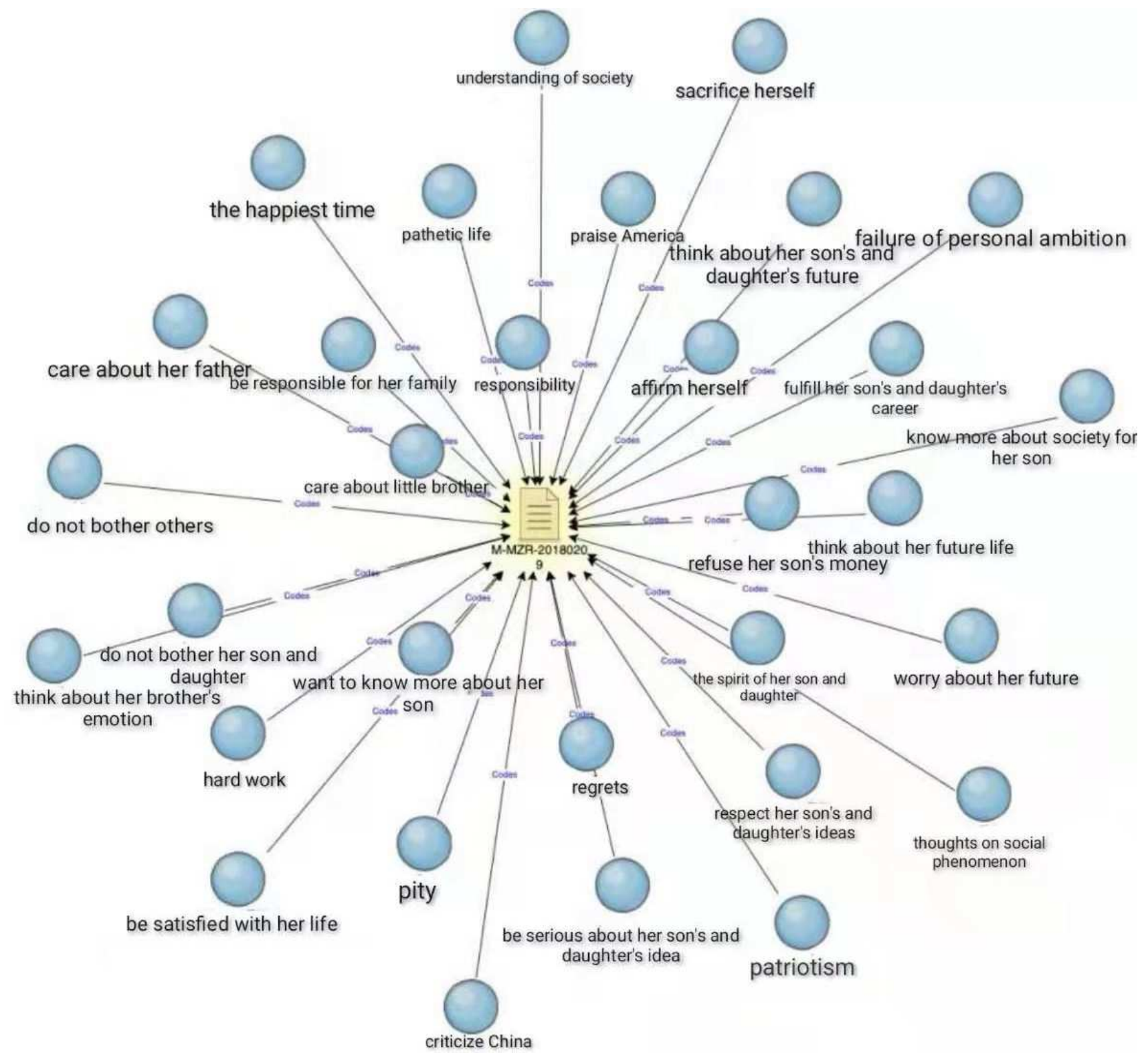

Figure 2. $M$ faces young $R$ two years later. 
Two days later, the staff said that $\mathrm{M}$ was in dementia in the afternoon after our interview, saying that others took her things away and knocked on her door at night. The researchers reflected on the feedback from nursing home managers. What have caused $M$ of suddenly showing the symptoms of Alzheimer's disease? This may not have any direct connection to our morning interview, or perhaps the morning interview that raised her expectations in life, leading to dissatisfaction with real life, and passive attacks on others.

On March 7, 2018, at the request of nursing home owner $\mathrm{H}$ 1 , R 1 tested $\mathrm{M}$ her cognitive ability. She could not help mentioning the difficulty of teaching a child and her loneliness. Speaking about her brother's skin and bones, she also said that she did not remember very well, especially when she could not even remember her account. Cognitive tests show she had no concept of seasonal and residential address names.

When dean $\mathrm{W}$ said that her son would be here she became excited before and after his coming, she would be suspecting people for stealing her electricity, suspecting that his nephew was greedy for her money, her brother-in-law stealing her money, and she kept harassing them with phonecallsregardless of their feelings.

Researchers ran nursing home management analysis and $\mathrm{M}$ behavior analysis, $M$ because of son coming, she wanted to express that she has backup, that her grievances can be expressed, or she wants to benefit her son, and the nursing home think $\mathrm{M}$ brought greater difficulties to their work, so they need to reevaluate her when her son is here, so as to improve the cost on $\mathrm{M}$.

On March 28, 2018, M volunteered to find the consulting room, saying that she needed R 1's company. The son left yesterday and would never return again. The son just came back, and she isn't sure if the son did came back, she stills thinks that the last time he came back was ten years ago. She is afraid of interfering her son's work and doesn't let him come. He would never see her again later. And when talked about tutoring her son to take high school, she thinks more of his son than his daughter. See Figure 3 for the details.

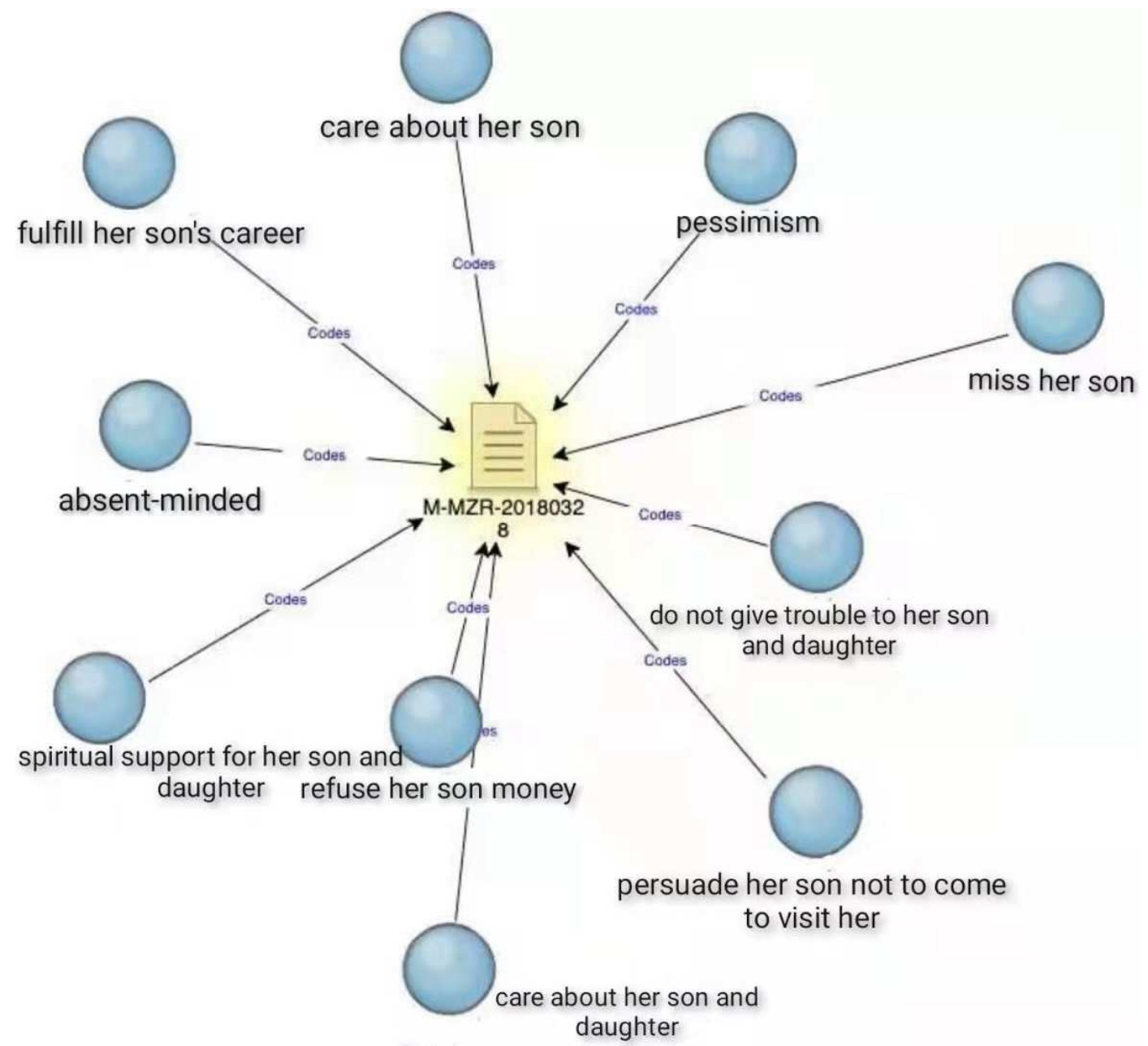

Figure 3. M's self-narrative points are facing $R 1$ after his son visits himself.

The struggles, contradictions, and pains of $\mathrm{M}$ can be seen in Figure 3. Her spirit lays on the children, but in order to fulfill the career of the children abroad, she has to persuade her son not to come back to see her, but she could not help but missing her son, full of pessimistic about life, she is such a contradiction, that she doubts whether her son really has came to see herself, she described herself in a trance. She has an unrealistic feeling of her life. 


\section{Conclusion}

The self-evolution of $\mathrm{M}$ is a problem of emotional disorder caused by means of important object loss. M's important object in childhood left one by one, including mother, brother, father and even husband, finally even the children are far away, which will undoubtedly arouse anxiety for all important object separation, her defensive strategy is to create and identify with a powerful object, such as Michurin, successful academic son, and even later observers. But none of these objects could meet the emotional companionship and life support she needed and so she got into trouble. She sees R and Dean W as objects of positive interaction, with hostility on her neighbors.

During the social loss of $\mathrm{M}$, she showed two types of response: positive and negative ones. The negative response is manifested by questioning others (or even their younger brother for their children) to stealing her property and harm her; the positive response is to ignore many events unfavorable to self-esteem, ignoring their disadvantages, and presenting a successful and false image in front of strangers (mainly to show herself) which is not conducive to the realistic evaluation of their situation and to establish a real and positive interactive relationship with their neighbors. Eventually the strategy she adopted was to form a superficial identity and false harmony with others around her.

In the later development of M's self, reality is increasingly blurred, reality gives way to feeling, fantasy, fictional history, memory phenomenon, self evolution gradually from the community retreat simple role exchange, impulse and perception, feeling and reflection. This demonstrates the process of self gain and loss: in the first half of the life, people get all kinds of understanding, know they have body, health, perception, character, metacognitive structure, consciousness, faith, etc., through social identity to obtain nationality, party, couples, parents, in the second half of life, people gradually lose these identity, lose consciousness finally lose health and body.

\section{Discussion}

Old people have less and less time in the future, so expects less and less social support from others, among which personal temperament plays an important intermediary role [6] whether their social interaction is positive or negative, goodwill or malicious to others, depends on their past experience of separation and symbiosis with important objects.

According to Zhang et al [7], aging attitude depends on the actual social support from the significant others the significant including spouse and children at core support level friends and siblings. Unfortunately, M's spouse has passed away; her children are living abroad under the pressure of survial. Her friends are all in Shanghai, and her sibling relationship is not good. At present, the only social support for her is from the fomal support system such as the government and institutions and other formal support system.

The deeper dilemma of $\mathrm{M}$ is that in the future time dimension, it is difficult for her to project her positive will to live, gratitude and goodwill to important objects (mainly children) and get respond. On the one hand, it is because of the space distance, on the other hand, it is because of the break in cultural values. According to the study of Wang et al [8], the higher the level of the filial piety the elderly expect from their children, the higher the level of social support they actually receive from their children, which will contribute to their happiness of the elderly in their later years. Unfortunately, the pattern of M's interactions with her children suggests that the higher her expectations of filial piety, the greater the gap between her and actual support. Research shows that lower expectations and actual support gap are positively correlated with life satisfaction [9], the larger the gap between expected support and actual support is, the older people's life is significantly correlated [10].

Peng and Yin's [11] research shows that in the acceptance and give child support, there is no significant difference between non-empty-nesters and empty-nesters in accepting and giving support to their children. In terms of receiving child support, service support is the most, followed by emotional and material support. For urban empty nesters, the more emotional they give their children, the less material support, the lower the level of depression. M presents a unique imbalance between receiving and giving support to children. The more emotional support $\mathrm{M}$ gives to children, the more it affects its current living conditions (for example, $M$ once said: If I don't think about it its good, but if I do...; If they didn't came its good, if they came I would be running up and down, sweating), she was unable to provide material support, which was a pity rather than a blessing for her (the house was sold and each of the children got RMB200,000), yet when they came back had no place to live, even $M$ herself lost her place to live. The children may also encounter an economic crisis abroad.

M's disappointment in the future significantly reduced her level of mental health and social support. According to Huang, $\mathrm{Li}$ and Wang [12], the subjective ages of ordinary people are lower than the actual age. The more subjective they feel closer to the actual age, the lower the quality of life, the more likely depression is. In the whole interview, her ego can be shown and settled to a certain extent, but her recent positivity can not show positive effects, Gong, Wang \& Fu [13] found that in recent memory, middle-aged and older women extracted more positive events from recent memory and rated them more positively than young women. So the M's self-evolution is a unique case. Her choice and the structure of the past ego jointly contributed to this result. Like this, $\mathrm{Z}$ mother-in-law and Uncle $S$ have been interviewed, but there are also negative cases, such as Z mother-in-law's lover, and the media retired $\mathrm{W}$ (manuscript).

In a word, the significant others are generally stable objects throughout the life-span, maintaining people's sense of life value. The loss of important objects in M's childhood left early trauma, and her excellent husband and promising children gave her a sense of life significance. Her children in her later years went abroad embedded in difficulties in identity and value identity, which activated the trauma of her early object 
loss and became the source of emotional conflict.

The self-evolution of $\mathrm{M}$ is followed by a cognitive impairment problem arising from the loss of self-value. According to McAdams's view, self is a dynamic construction process that has both personal experience as the basis of empirical material and conceptual selection as the framework of meaning interpretation. Self-reporting has the function of forming identity. The creation of life stories can bring a sense of unity, integrate different self, and let us die in satisfaction is our answer to "being". The development of each of us is similar from childhood to adolescence, but the age from middle age to old age is full of individuality, especially self-identity of culture, creation and summary of stories. The elderly with dementia will reject their own story, and it will be too late to recreate one. Self - narration includes unique narrative tone, personal imagery, thematic lines, ideological background, key scenes, conflicting roles, expectations of their own future outcomes. Among them, agency can prevent dementia, while communication excessive may aggravate deqmentia by over emphasizing it.

From the perspective of social others construction, $\mathrm{M}$

The inability to integrate the role of parents defined by their children with the role of elders defined by real life, she fell into a dilemma of interpersonal interaction, and showed denial, belittling and extreme attitude towards reality, degradation and finally formed an attitude of indifference rather than acceptance toward death. That is to say, dementia old people are not without their own life story, but the integration of story is a pathological defense. $\mathrm{M}$ did not realize the unity of individuals, others and society. There is no unity of individuals, others and society, no balance between the role of subjectivity and the role of communion. Their self-repoting becomes more and more divorced from reality, resulting in serious conflicts about the plots between self -constructed personal stories and stories constructed by others, and eventually being socially story constructed as "Senile dementia patients".

Etymologically, Alzheimer's is a concept from the English discourse system, and in the cognitive history of the disease, people cannot be recognized scientifically, for a long time, even moral evaluation or personality discrimination against the patient. Since modern times, although it was liberated from the crazy and rational confrontation of the French philosopher Foucault, who so-called the "classical period", it is classified into the medical system of mental diseases and specifically named after Alzheimer's disease. But still with a negative label, and has been on the road of reductionism, in gene, neurophysiology, and ignore the dementia as a concept constantly constructed, so the huge support of medical projects are declared bankruptcy, but rich environmental support of the retarded elderly can improve the behavior mode [14].

As an age-related psychiatric concept constantly constructed by the society, senile dementia may be used by young people or medical staff as a tool to deconstruct the voice of the elderly [15]. On the positive side, when an old man is confused, he may be trying to laugh at himself and be forgiven. On the negative side, a person with senile dementia will refer to the old person who is not happy and causes trouble. If the old person identifies with this negative label in self-construction, it will aggravate the symptoms of dementia.

The findings of this study are that geriatric observation provides a possible intervention path for such cases. Continuous observation or even interviews by the researchers or volunteers on the elderly will gradually become an important object with social support and stimulate her enthusiasm to identify with the objects. Most of the researchers involved in the observation have a positive perspective and have relatively ample time in the future, such as student volunteers, which will give the case owner the opportunity to tell and arouse his or her function of active social interaction.

\section{Funding}

Supported by "the Fundamental Research Funds for the Central Universities (WUT: 2021VI019).

\section{References}

[1] Wang, T., \& Hou, C. (2016). A Topical Structure Analysis on Chinese Aging Study and Practice in the View of Culture Psychology. In Tian Xie, Lisa Hale, and Jin Zhang (eds) Proceedings of the Second Summit Forum of China's Cultural Psychology (pp. 164-170), The American Scholars Press.

[2] Wang, T., \& Yu, Z. (2018). The Study on Aging Psychology According to the Elderly Care under the Glocalization Perspective. International Journal of Culture and History, 4 (4): 109-113.

[3] Rodin, J., \& Langer, E. (1980). Aging Labels-the Decline Of Control And the Fall Of Self-Esteem. Journal Of Social Issues, $36(2), 12-29$.

[4] Neugarten, B. L., \& Neugarten, D. A. (1996). The meanings of age: selected papers of Bernice L. Neugarten Chicago: University of Chicago Press, p. 381.

[5] Wang, T, Guo, Z. \& Zhang, Y. (2019), The Social Construction of the Senile Dementia Based on the Self-Statement by an 80-year Aged. Advances in Social Science, Education and Humanities Research, 298: 317-325.

[6] Casu, G., Gentili, E., \& Gremigni, P.. (2020). Future time perspective and perceived social support: the mediating role of gratitude. International Journal of Environmental Research and Public Health, 17 (18).

[7] Zhang Mingyan, Wang Dahua, Mick Power, \& Keb Laidlaw. (2011). Characteristics of the Senior Important Social Support and Their Relations to the Aging Attitude. Psychological Science, 034 (002), 441-445.

[8] Wang Dahua, Shen Jiliang, Tong Yan, Fei Guanghong. (2003). Filial piety and social support. Psychological Science (3), 400-402.

[9] Gow, A. J., Pattie, A., Whiteman, M. C., Whalley, L. J., \& Deary, I. J.. (2007). Social support and successful aging: investigating the relationships between lifetime cognitive change and life satisfaction. Journal of Individual Differences, 28 (3), 103-115. 
[10] Xu Yuan, Hao Zhen. (2007). Study on the impact of access, expectation, and utilization of elderly social support on senior life satisfaction. Science and Education, Arts Exchange, 222-223. (In Chinese).

[11] Peng Huamao, \& Yin Xuefei., (2010). Parent-child support for urban and rural empty-nesters and their relationship to depression. Mental Development and Education (06), 627-633. (In Chinese).

[12] Huang Tingting, Li Yun, \& Wang Dahua. (2017). Effect of elderly subjective age on quality of life: mediation between depression and anxiety. Chinese Journal of Clinical Psychology, 025 (001), 127-131. (In Chinese).
[13] Gong Xianmin, Wang Dahua, \& Fu Yan. (2013). Phenomenological experience of adult women: the Role of Age and Time. Psychological Science (05), 1101-1105. (In Chinese).

[14] Xin Fengdi \& Zhang Yanrong. (2018). Alzheimer's disease: From Classical madness to Alzheimer's disease. Medicine and Philosophy (B), v. 39; No. 599 (06), 98-101. (In Chinese).

[15] Gao Jie. (2016). Cases of Alzheimer's psychological counseling. Chinese Journal of Health Psychology, 24 (2), 317-320. (In Chinese). 